\title{
Moncorvo Filho e algumas histórias do Instituto de Proteção e Assistência à I nfância
}

\section{Moncorvo Filho and some stories about the Institute for the Preservation and Assistence of Children}

\author{
Nelson Gomes de Sant' Ana e Silva J unior* \\ Docente da Universidade Federal da Paraíba - UFPB, João Pessoa, PB, Brasil
}

\section{Renata Monteiro Garcia**}

Docente da Universidade Federal da Bahia- UFBA, Barreiras, BA, Brasil

\begin{abstract}
RESUMO
O Movimento Higienista teve grande impacto nas políticas públicas brasileiras do final do século XIX e início do século XX, dando destaque à proteção e cuidados com a infância. Tal preocupação, influenciada diretamente por aportes teóricos oriundos da Europa, teve em Carlos Arthur Moncorvo Filho um de seus principais representantes no país. O objetivo deste artigo é analisar algumas histórias do Instituto de Proteção e Assistência à Infância (IPAI) e dos anexos criados junto a ele, idealizados pelo próprio Moncorvo Filho. Ao longo das análises, pôde-se perceber 0 quanto discursos e práticas de proteção à infância carregavam em si estratégias de normatização de condutas e moralização social. Retomar algumas histórias ligadas à preservação da infância no Brasil é de grande importância para a Psicologia e demais Ciências Humanas e Sociais. Tal estratégia tende a possibilitar aos especialistas de hoje refletir sobre a prática profissional e avaliar que modelos estão sendo produzidos ou reproduzidos nestas práticas.
\end{abstract}

Palavras-Chave: Infância, Proteção, Moncorvo Filho, Higienismo

\begin{abstract}
ABSCTRACT
The Hygienist's Movement had a big impact on Brazilian public policy at the end of XIX century and beginning of XX century, shedding light on child's protection and care. That question was directly influenced by European theories. Carlos Arthur Moncorvo Filho was a major representative in the country. This paper aims at analyzing some stories that happened at the Institute for the Preservation and Assistence of Children and its extensions. The medical doctor Moncorvo Filho founded these clinics. Through analyses, it is possible to notice that discourse and practices toward children's protection carry strategy and standardize behavior and social moral. Retelling some stories linked to childhood preservation in Brazil is vital to psychology and others human and social sciences. Such a strategy enables specialists at present to reflect upon professional practices and to evaluate models that have been produced or copied in these practices.
\end{abstract}

Keywords: Childhood, Protection, Moncorvo Filho, Health Awareness 


\title{
I ntrodução
}

Ao lançarmos o olhar para o final do século XIX no Brasil, podemos perceber a emergência de várias mudanças no cenário político, econômico e social brasileiro, como a proclamação da República, a abolição oficial da escravatura e a entrada de imigrantes no país, formando um grande contingente humano nos centros urbanos. As cidades cresceram em ritmo acelerado ganhando especial interesse dos especialistas após as mudanças produzidas pelo desenvolvimento industrial. Este trouxe consigo, além de transformações tecnológicas, econômicas e demográficas, novos conceitos, valores e subjetividades (COSTA, 1999).

Problemas relacionados à moradia, à miséria e ao desemprego, aliados a uma preocupação sanitária em função das taxas de mortalidade infantil e da grande difusão de casos de sífilis, tuberculose e alcoolismo, preocuparam estudiosos e políticos do período, caracterizando o espaço urbano como alvo de uma série de intervenções, tornando-o um objeto a ser ordenado, reformado e disciplinado. Naquele momento, pode-se afirmar que tais tarefas foram atribuídas principalmente aos médicos, mas que contou também com o trabalho de sociólogos, políticos, pedagogos e juristas. (JOSEPHSON, 1994). Ganhou vulto, em meio a isto, o movimento higienista que, inserindo-se nas políticas públicas, foi legitimado por saberes científicos, tidos como neutros e absolutos, numa tentativa de dar conta de todas as "mazelas" que assolavam a sociedade da época. (CAPONI, 2000; LOBO, 1995).

\begin{abstract}
Abriu-se campo para a proliferação de tecnologias e para o trabalho de especialistas que investigavam sobre a saúde dos imigrantes, a situação sanitária dos portos, o dia-a-dia das cidades, a higiene infantil, os hábitos e os costumes populares, a eugenia ou 'ideal de branqueamento' do povo brasileiro, o trabalho fabril, o mundo do crime etc. O discurso médico higiênico acompanhou o início do processo de transformação política e econômica da sociedade brasileira em uma economia urbano-comercial e expressou o pensamento de uma parte da elite dominante que queria modernizar o país. (MANASERA; SILVA, 2000, p. 117, grifo nosso)
\end{abstract}

A preocupação com o desenvolvimento do país que acabara de se tornar uma República e, por isso, era considerado um "país criança", inseria-se em inquietações eugênicas que pregavam que sua população deveria ser de gente saudável e, para que o Brasil pudesse se tornar uma grande nação, era preciso criar mecanismos de regulação social, principalmente para dar conta das "classes inferiores" e "portadoras de degenerescências", cujos problemas eram de ordem social e moral. De acordo com os preceitos 
eugênicos, "Purificando a raça" galgaríamos importantes degraus na "escala evolutiva".

Imbuídos do ideário do saneamento moral, os higienistas lançaram seus olhares e cuidados principalmente sobre os pobres, as prostitutas, os loucos, os cortiços, as crianças e todos os locais/grupos que, segundo eles, de alguma maneira, precisariam ser tutelados para que melhorassem suas condições de higiene e não oferecessem danos ao restante da população.

\begin{abstract}
Assim, seduzidos pela idéia de uma 'ciência' que anunciava medidas decisivas para resolver o grande problema da composição racial do brasileiro, condição de possibilidade da construção da nação, os intelectuais brasileiros, sobretudo os médicos vão aderir à causa eugênica. (...) De fato, impregnados de um biologismo teórico até certo ponto fatalista, que os levava a encontrar novos degenerados a cada esquina, os psiquiatras se mostravam fascinados pelas possibilidades reparadoras da eugenia. (REIS, 2000, p. 7)
\end{abstract}

Em meio a esse movimento podemos destacar a importância que a figura da criança passa a tomar nos discursos médicos, pedagógicos e jurídicos da época. Proteger a criança passa a ser prioridade, pois seria a partir do cuidado com os pequenos que estaríamos evitando o desenvolvimento de futuras degenerescências, fardos e perigos sociais. Neste momento, os discursos sobre a infância eram especificamente discursos de prevenção e profilaxia. (COSTA, 1999; FREITAS, 1997; OLIVEIRA, 1999; RAGO, 1985; REIS, 2000; RIZZINI, 1997; WADSWORTH, 1999)

O saber higienista passou a ecoar em instituições como a escola, o hospital, a família etc. sob o argumento da proteção à infância, normatizando condutas, docilizando corpos e delimitando fronteiras entre o normal e o patológico. Segundo os higienistas, as famílias deveriam ser núcleos particularizados, lares "santos" em que a mulher seria a "rainha do lar" e a criança o "reizinho da casa", onde qualquer desvio poderia implicar na culpabilização desta família que não foi suficientemente boa (e competente) para educar o seu filho, justificando a intervenção do Estado. O lar burguês tornou-se referencial e modelo sanitário, moral e arquitetônico das condições de existência na cidade.

O interesse pela infância, nitidamente mais aguçado e de natureza diversa daquela observada nos séculos anteriores, deve ser entendido como reflexo dos contornos das novas idéias. A criança deixa de ocupar uma posição secundária e mesmo desimportante na família e na sociedade e passa a ser percebida como valioso patrimônio de uma nação; como 'chave para o futuro', um ser em formação - 'ductil e moldavel' - que tanto pode ser transformado em 'homem de bem' (elemento útil para o progresso da nação) ou num 
'degenerado' (um vicioso inútil a pesar nos cofres públicos). (RIZZINI, 1997, p. 25)

A história da proteção à infância no Brasil foi marcada pela emergência do modelo de família baseado nos moldes burgueses e normatizado pelo saber científico que logo ganhou espaço no meio jurídico e produziu "legalidade", legitimando a ação do Estado junto àqueles que se constituíssem enquanto desviantes de determinadas normas sociais vigentes. Sendo assim, ainda no final do século XIX, destacamos a fundação do Instituto de Assistência e Proteção à Infância do Rio de Janeiro (IPAI) pelo médico Carlos Artur Moncorvo Filho em 1899.

A escolha pelo IPAI como instituição a ser analisada neste estudo deve-se ao fato do mesmo ter despontado como modelo para outras instituições que proliferaram pelo país, servindo como referência para os especialistas interessados pelo tema da infância. Além disso, Moncorvo Filho pode ser considerado uma das figuras públicas mais importantes tanto na difusão de preceitos higiênicos para as famílias quanto nas ações voltadas para a proteção à infância no Brasil.

Compreendemos que analisar o IPAI e algumas de suas histórias constitui-se como um importante dispositivo para problematizarmos as relações de saber - poder que, historicamente, têm se estabelecido em muitas das práticas de proteção à infância. Desta forma, é possível pensarmos, ainda, como uma série de discursos de proteção carregam em si engrenagens sutis de classificação, exclusão e normatização social.

\section{O Instituto de Proteção e Assistência à I nfância (I PAI )}

Para Moncorvo Filho "a mortalidade infantil era um flagelo nacional" (1917, p. 82). Os discursos pautados na idéia de que a criança constituiria o futuro da nação tinham nas estatísticas da mortalidade infantil e do abandono de crianças o retrato de uma realidade pouco promissora para o país. Em discurso no Senado Federal no ano de 1896, Lopes Trovão fazia alusão ao tema da salvação da criança:

\footnotetext{
Por isso, senhores, como recurso supremo, eu me volto para a infancia _ os pequeninos de hoje que serão os grandes de amanhã; é nella que ponho as esperanças da grandesa do actual regimen pela regeneração da patria. (...) Temos uma patria a reconstruir, uma nação a firmar, um povo a fazer... e para emprehender essa tarefa, que elemento mais ductil e moldavel a trabalhar do que a infancia?! (apud MONCORVO FILHO, 1922, p. 131-133)
}

Tornava-se iminente a necessidade de um projeto assistencial que instituísse uma estratégia de controle sobre a população pobre de modo a garantir, por um lado, a promoção do bem estar daqueles 
indivíduos e, por outro, que estes grupos estivessem vigiados de forma a promover uma certa ordem social.

O sistema de assistência caritativa liderado pela Igreja tornava-se cada vez mais desgastado, assim como suas relações com o Estado. Tal modelo, liderado principalmente pelas Ordens Religiosas, estava pautado na doação aos pobres para a salvação da alma do doador. Os asilos de caridade comandados pelas Irmãs de Caridade, assim como o sistema da Roda dos Expostos, começaram a ser questionados por sua falta de cientificidade. Além disso, o modelo caritativo já não era capaz de atender plenamente à população pobre que se multiplicava a cada dia nos centros urbanos.

A filantropia revelou-se como a melhor estratégia para dar conta da assistência à população pobre: atendendo à realidade da sociedade moderna em que o Estado liberal era solicitado apenas para a fiscalização, coube à iniciativa privada a execução de projetos voltados para o bem-estar da população através de iniciativas particulares em que seus idealizadores estavam imbuídos de um sentimento patriótico.

O viés filantrópico tinha como objetivo cuidar do corpo e da moral entregues à ignorância, propensos aos vícios e à degradação. Cabia, assim, aos homens cultos o dever patriótico de resgatar estes indivíduos pertencentes às classes pobres a quem se atribuía falta de saber sobre a gestão de suas vidas. Por isso, ofereciam conselhos pautados em preceitos científicos, bem como doações fiscalizadas que permitiam, por um lado, o controle daquele que a recebia e, por outro, a utilidade destas doações, além de serviços básicos. Enfim, a filantropia pretendeu uma assistência que utilizava mecanismos reguladores para cumprir sua missão de cunho científico e moral.

A partir destas concepções, Moncorvo Filho idealizou o IPAI. Relata sua iniciativa da seguinte forma:

O tempo corria e cada vez mais iamos armazenando estudos
e observações quer no terreno da hygiene infantil, no qual as
estatísticas mostravam a excessiva mortalidade dos
pequeninos, certamente em grande parte evitavel, quer na
esphera do abandono moral, quer ainda no tocante aos
deploráveis desastres da ignorancia, do preconceito e do
analphabetismo. (1922, p. 127-128)

Destaca que logo ao se formar lhe faltavam o prestígio social e o patrimônio necessários para iniciar este projeto. Entretanto, a morte de seu primeiro filho foi o estímulo que precisava para empregar maior interesse no Instituto.

Um facto intimo que a fatalidade houvéra consentido desolasse o nosso lar _ qual o da perda do primeiro filho _, paradoxalmente nos emprestou energia para que fizéssemós 
o vóto de cuidar, com masculo interesse, das creancinhas desherdadas da fortuna e eis como nos atirámos com ardor justificavel á uma acção decisiva e, pensavamos, util á nossa patria. (MONCORVO FILHO, 1926, p. 128)

O modelo produzido no IPAI foi um exemplo claro da filantropia desejada na época: prestava de forma gratuita os serviços básicos de saúde, dentro dos padrões científicos, exigindo da população assistida a obrigação de frequentar as palestras de higiene proferidas no próprio Instituto. As doações não podiam ser feitas sob a forma de dinheiro, pois não teriam como controlar o que seria feito deste, mas recebiam e distribuíam gratuitamente leite, alimentos, roupas, remédios e calçados.

Representante do modelo assistencial filantrópico, Moncorvo Filho acreditava na ciência como promotora de assistência à população visando à prevenção de problemas futuros. A primeira iniciativa que tomou visando a fundação de um instituto que privilegiasse suas idéias foi pesquisar as instituições, fossem elas públicas ou privadas, existentes na antiga capital da república, que tinham por fim amparar e recolher as crianças desvalidas. Em consonância com o modelo de conhecimento de sua época, Moncorvo Filho lançou-se na investigação de seu objeto, tratando de apontar as deficiências dos estabelecimentos existentes e de sustentar a necessidade de uma instituição que tivesse como pilares a assistência filantrópica e os preceitos higiênicos. Tais pesquisas proporcionaram um minucioso estudo sobre a situação da infância no Rio de Janeiro e tornaram-se trabalhos publicados em revistas científicas e em jornais diários, com o intuito de divulgar tais resultados.

Sobre as condições dos asilos, Moncorvo Filho (1922) comenta:

Ora, o "asylo", tal qual o concebiam os antigos, era uma casa na qual encafurnavam dezenas de creanças de 7 a 8 annos em diante nem sempre livres de uma promiscuidade prejudicial, educádas no carrancismo de uma instrucção quasi exclusivamente religiosa, vivendo sem o menor preceito de hygiene, muitas vezes atrophiadas pela falta de ar e de luz sufficientes, via de regra pessimamente alimentadas, sujeitas, não raro,á qualquer leve falta , a a castigos barbaros dos quaes o mais suave era o supplicio da fôme e da sêde, aberrando, pois, tudo isso dos principios scientificos e sociaes que devem presidir a manutenção das casas de caridade, recolhimentos, patronatos, orphanatos, etc., sendo, conseguintemante os asylos nessas condições instituições condemnaveis. (p. 134)

Ocorre que tanta divulgação não surtiu o efeito esperado. A "apatia dos governantes" não permitiu que auxílios oficiais fossem aprovados para o início dos projetos de Moncorvo Filho; contudo, isto não o paralisou. Determinado a realizar uma cruzada em prol da infância, 
objetivou estabelecer uma enérgica e extensa propaganda de higiene infantil para que, enfim, o Brasil pudesse estar à altura dos países desenvolvidos.

Desta forma, em 24 de março de 1899, na Rua da Lapa, n 93, no Rio de Janeiro, residência de Moncorvo Filho, deu-se a fundação do Instituto de Protecção e Assistencia á Infancia do Rio de Janeiro, em uma reunião que contou com a presença de diversas personalidades da capital da República, entre médicos, juristas, políticos e pessoas da alta sociedade ${ }^{1}$, personalidades que apoiavam a iniciativa daquele médico e compartilhavam dos ideais higiênicos.

Tanto prestígio não garantiu recursos suficientes para a instalação imediata do Instituto. Somente em 14 de julho de 1901 ocorreu a instalação da sua primeira seção (nomeada Dispensário Moncorvo) em um prédio alugado na Rua Visconde do Rio Branco, $\mathrm{n}^{\circ} 22$, inauguração que contou com a presença do presidente da República, Campos Sales.

O Dispensário tinha como modelo aquele criado pelo Dr. Gibert, em 1875, na cidade de Havre, na França, dedicado ao tratamento de crianças doentes e indigentes ${ }^{2}$, não se restringindo apenas aos cuidados com o corpo, mas, sobretudo, ao tratamento do que chamava miséria moral dos indivíduos.

\begin{abstract}
Uma bôa moral é, por vezes, a melhor hygiene do corpo, o verdadeiro meio prophylatico contra a molestia. Bem comprehendida, ella é sempre util e o seria, ainda que fôsse possivel negar a sua influencia sobre a saude do côrpo, porquanto alguma cousa há superior á saude, preferivel á vida - é a honra; e para desenvolver os sentimentos da honra e da virtude preciso se tórna fallar á inteligencia e sobretudo ao coração, quer dizer, moralisar o individuo. (MONCORVO FILHO, 1922, p. 146)
\end{abstract}

Entre os objetivos formulados no Programa do Instituto podemos destacar os seguintes: proteger as crianças pobres, doentes, defeituosas, maltratadas e moralmente abandonadas; difundir entre as famílias pobres e proletárias noções elementares de higiene infantil; promover a inspeção higiênica médica das escolas públicas e particulares que funcionem na capital da república; inspecionar as atividades das amas de leite.

Em seu programa de assistência, o Instituto oferecia os seguintes serviços: Ginecologia e exame de mulheres grávidas, Exame clínico infantil, Vacinação, Distribuição de roupas, Gota de leite (distribuição de leite esterilizado), Exame de atestação de amas de leite. O Dispensário funcionava das 7 às 17 horas, contando com salas próprias para cada especialidade e os serviços funcionavam em horários diversos para evitar o acúmulo de pessoas na sala de espera. 
Somando-se à preocupação em oferecer um cunho científico a esta instituição, podemos citar, ainda, duas importantes iniciativas dos profissionais do Instituto: a Sociedade Científica Protetora da Infância e os Archivos de Protecção a Infancia.

A primeira, fundada em 28 de junho de 1902, era composta pelos profissionais que atuavam no IPAl e, portanto, tinha como característica principal ser um grupo exclusivamente masculino, já que havia uma divisão hierárquica entre homens e mulheres, destinando-se ao homem a função intelectual, o trabalho fora de casa e à mulher as responsabilidades do lar, assunto que trataremos mais adiante. Novamente, será Nascimento Gurgel nos Archivos de Protecção a Infância (1902) quem descreverá a iniciativa desta sociedade:

Propositalmente deixamos para falar em ultimo lugar, do fato mais saliente no movimento científico de nosso Instituto, isto é, a fundação da "Sociedade Científica Protetora da Infância", destinada a discutir todas as questões referentes à assistência à infância e da qual fazem parte todos os membros do corpo profissional científico do Instituto.(...) Representa a primeira sociedade de Pediatria fundada no Brasil. (p. 27)

De acordo com Moncorvo Filho:

O valor científico daquele centro de labuta profissional e humanitária revelou-se, de um lado, com o aparecimento de varias teses de doutoramento defendidas perante nossa Faculdade de Medicina e, de outro, com a fundação no seio do próprio Instituto e a ele anexada da Sociedade Científica Protetora da Infância. (1922, p. 151)

Por sua vez, os Archivos começaram a circular em novembro de 1902, sendo o órgão oficial de divulgação dos trabalhos do IPAI. A revista era composta por artigos, Noticiário, Conferência de Higiene Infantil, Parte Literária (divulgação de poesias), Livro de Visitantes (reproduzia-se, em cada número, as mensagens deixadas no livro de visitas do Dispensário), fotos e anúncios. Os custos com a publicação dos periódicos eram cobertos pelos anunciantes, em sua maioria fabricantes de medicamentos.

O patrimônio do IPAI estava concentrado em apólices da dívida pública, inscrições do Banco da República dos Estados Unidos do Brazil, dinheiro em depósito na Caixa Econômica, renda que não era suficiente para manter a instituição. Contavam, então, com as contribuições dos associados fundadores, beneméritos, honorários, protetores e contribuintes - categorias que tinham um valor fixo 
específico para cada uma - além do resgate mensal dos cupons de passagens das companhias de bondes em favor do Instituto.

\section{As mulheres e o I PAI}

Outro importante grupo anexo ao Instituto foi o das "Damas da Assistência à Infância", formado por senhoras das classes mais abastadas, empenhadas em seu papel difusor do modelo de família nuclear em que a mulher exerceria sua "vocação" para a maternidade. Fundada em 5 de setembro de 1906 esta associação é bem descrita nestes trechos de seus Estatutos:

Art. $1^{\circ}$ A Associação "Damas da Assistencia á Infancia", fundada nesta cidade do Rio de Janeiro, onde tem sua séde, compõe-se de numero ilimitado de socias e se rege pelos presentes estatutos.

Art. $2^{\circ}$ Toda a senhora de moralidade reconhecida e maior de quinze anos, poderá pertencer á associação.

Art. $4^{\circ} \mathrm{A}$ associação considera parte integrante dos presentes Estatutos, o programa do "Instituto de Proteção e Assistência á Infancia do Rio de Janeiro" e tem por fins especiaes:

a) Promover por meios de proteger efficazmente a infancia pobre, proporcionando-lhe os cuidados de que carecer;

vida;

b) Angariar objetos que lhe possam ser uteis á

c) Incumbir-se, pelo trabalho de suas socias, da confecção de vestes e do tratamento das creanças, quando enfermas;

d) Offerecer ás creanças pobres festas e brinquedos por occasião do Natal, Anno Bom e Reis;

e) Auxiliar o Conselho Administrativo do Instituto de Protecção e Assistencia a Infancia do Rio de Janeiro, sempre que solicitar sua coadjuvação para a fiel execução do seu programma;

f) Promover pelos processos que forem mais proficuos ao fim que deseja attingir, os recursos que 0 Instituto precisar para a sua permanente e condigna installação. (Archivos de Assistencia á Infancia, 1907, p. 19)

Organizado pelo próprio Moncorvo Filho, o grupo das Damas da Assistência tinha como função a confecção de roupas para crianças carentes, a preparação de material médico, a organização de festas e a arrecadação de donativos.

A obra de caridade das Damas consolidava hierarquias de classes e de gêneros na medida em que enfatizava o papel da mulher como esposa, mãe e provedora, além de propiciar, simultaneamente, oportunidade para que as mulheres da elite exercitassem seu talento, despendessem suas energias, abrindo-Ihes ainda uma porta de entrada legitima para a vida 
pública. Tal sistema não ameaçava os profissionais do sexo masculino, pois canalizava as energias femininas para atividades percebidas como extensões naturais da maternidade e da esfera doméstica. (WADSWORTH, 1999, p. 4)

O papel destinado às mulheres que compunham as Damas da Assistência estava em conformidade com os padrões sociais vigentes: - lar e o cuidado com os filhos eram sua principal ocupação, a qual se somava somava a virtuosa função moralizadora junto à obra filantrópica. Tal função não comprometia sua missão de mãe, nem tampouco Ihe exigia iniciativa ou participação decisória. Nas palavras de Moncorvo Filho:

A mulher quasi sempre bondosa e meiga _ pensamento inclinado para o bem, - com encantadôra meiguice olhos fitos nos filhos, prodigalisando-lhes o carinho, o afago, a educação e os bons sentimentos, não raro se constitue um verdadeiro anjo do lar! (MONCORVO FILHO, 1915, p. 7)

Rago (1985), por sua vez, aponta que este modelo de mulher, difundido junto às classes mais pobres a partir do início do século $X X$, desempenhou um papel fundamental na emergência da família nuclear moderna.

Assim, constituiu-se um padrão de feminilidade que destinava à mulher os cuidados com o lar, cabendo-lhe, no máximo, as ocupações caritativas, como era o caso das Damas da Assistência. A formação intelectual, o domínio público, o trabalho, cabiam ao homem. Os atributos da racionalidade, a capacidade de tomar iniciativas e a "vocação" para o poder faziam parte da "natureza" masculina, segundo este discurso.

Certamente, a construção de um modelo de mulher simbolizado pela mãe devotada e inteira sacrifício, implicou sua completa desvalorização profissional, política e intelectual. Esta desvalorização é imensa porque parte do pressuposto de que a mulher em si não é nada, de que deve esquecer-se deliberadamente de si mesma e realizar-se através dos êxitos dos filhos e do marido. (RAGO, 1985, p. 65)

A ocupação no cuidado com os filhos, com o lar e com o marido, fazia da mulher a principal aliada dos médicos, devendo estar atenta ao perigo das doenças físicas e morais, educando seus filhos, vigiando seu marido, guardando seu lar.

Dumas Filho já confessára que “a maternidade é o patriotismo da mulheres..." e na Obra da solidariedade humana, _ pergunto eu,_ quem mais coopera para a epopéia do futuro da Pátria? (MONCORVO FILHO, 1925, p. 8) 
O interesse da medicina pela mulher implicava, principalmente, na luta contra os saberes populares das parteiras e comadres, cujas práticas eram consideradas inúteis e perniciosas. Tal desqualificação também foi usada como estratégia na tentativa dos médicos de uma aliança com a figura da mulher-mãe. Por outro lado, na análise da situação francesa por Donzelot - que consideramos adequada à realidade brasileira - esta aliança também foi proveitosa para as mulheres burguesas que ganham um novo poder na esfera doméstica a partir da importância maior que adquirem nas funções maternas (DONZELOT, 1986).

Segundo Costa (1999), a urbanização foi um dos fatores que promoveu a figura da mulher consumidora de produtos industrializados, do comércio e da moda européia, além de possibilitar que se instruísse mais através de novelas e romances. É claro que sua independência, naquela época, não foi além disto: sua presença nas catedrais da ciência era intolerável, isto ultrapassava o limite de segurança social. Matos (2002) aponta que a mulher, neste modelo, estava submetida ao homem devido à sua "predestinação biológica", pois, sujeita às limitações da gravidez e da menstruação, não deveria se desviar de seu destino natural.

O útero definia a função social e as capacidades e limitações
femininas, determinava seu comportamento emocional e
moral, produzindo um ser incapaz de raciocínios elaborados,
abstrações e atividade intelectual, mais frágil do ponto de
vista físico e sedentário por natureza. A combinação de
fragilidade intelectual e física e de sensibilidade emocional
tornava as mulheres preparadas para a procriação e a
criação dos filhos. (MATOS, 2002, p. 4)

A história nas famílias populares ocorre por outro viés, embora seja claro que a preocupação é a mesma: garantir a conservação das crianças e divulgar os preceitos higiênicos. Só que, neste caso, através de uma economia bem diferente, trata-se de estabelecer "vigilâncias discretas" (DONZELOT, 1986), o que, no caso brasileiro, ocorreu através das práticas de assistência que emergiram no início do século $X X$.

As práticas filantrópicas atuaram através do viés sanitarista e educacional. No caso do Instituto, vemos claramente como tais práticas serviram de aliadas para manter sob tutela uma população carente de serviços e de informação. Serviços básicos de saúde eram oferecidos, assim como alimentos, roupas, brinquedos, enfim, itens necessários para aquela população tão pobre, desde que as mães assistissem às palestras sobre higiene infantil ministradas no IPAI.

Dessa maneira, vigiadas pelos relatórios deixados nas fichas de atendimento sobre o cuidado com os filhos, alertadas de sua grande 
parcela de responsabilidade em relação à vida destes, instruídas sobre a maneira correta de criar as crianças e gerir seu lar, as mães eram controladas por mecanismos de poder articulados pelos que produziam o saber dominante.

Tudo isto acabou por produzir subjetividades submissas a um saber que ditava normas e padrões de moralidade, por exemplo, associando as causas da tuberculose ao consumo de álcool e atribuindo-se ainda a este o nascimento de filhos defeituosos, epiléticos ou com problemas mentais. Somam-se a estes fatores também a intimidação, a ditadura de comportamentos, a associação de idéias preconceituosas para combater hábitos que afastassem homens ou mulheres do padrão esperado.

Segundo Moncorvo Filho até o ano de 1929 o IPAl distribuiu mais de 1 milhão de impressos com conselhos de higiene às mães o que "revela o patriótico interesse com que procurámos concôrrer para o melhoramento de nossa gente." (1929, p. 14)

\section{O Concurso de Robustez e os I deais Eugênicos}

Durante as comemorações do Dia das Crianças $^{3}$, que aconteciam no dia 12 de outubro, havia sessões grátis de filmes, além de jogos, exposições de escoteiros, paradas, partidas de futebol e missas, mas um dos eventos mais importante deste dia era o Concurso de Robustez ${ }^{4}$.

O Concurso tinha como objetivo premiar as mães que apresentassem os bebês mais saudáveis e que tivessem sido alimentados exclusivamente pelo leite materno pelo menos até os seis meses. Para participar, as mães deveriam apresentar atestado policial comprovando sua pobreza e as crianças deveriam ter no máximo um ano de idade.

Efetivamente, não havia como comprovar que as crianças eram realmente amamentadas pelo leite materno. Independentemente disto, a comissão julgadora, composta por um júri de médicos convidados pelo Instituto, avaliava diversas crianças inscritas por suas mães no concurso. Afinal, o prêmio em dinheiro destinado ao primeiro e segundo classificados representava uma boa quantia.

Os ganhadores do primeiro Concurso, realizado pelo Instituto no ano de 1902, tiveram suas fotos publicadas num periódico de destaque da época, a Revista da Semana e no próprio periódico do IPAI, os Archivos de Assistência á Infancia. As fotos apresentam duas crianças muito gordas e brancas. Nas legendas encontramos as seguintes informações: " $1^{\circ}$ Prêmio - Tupan, 7 meses, $9.740 \mathrm{Kg}$., 65 cm." e "2 Prêmio - Constantino, 5 meses, $11.400 \mathrm{Kg}$., $68 \mathrm{~cm}$." 


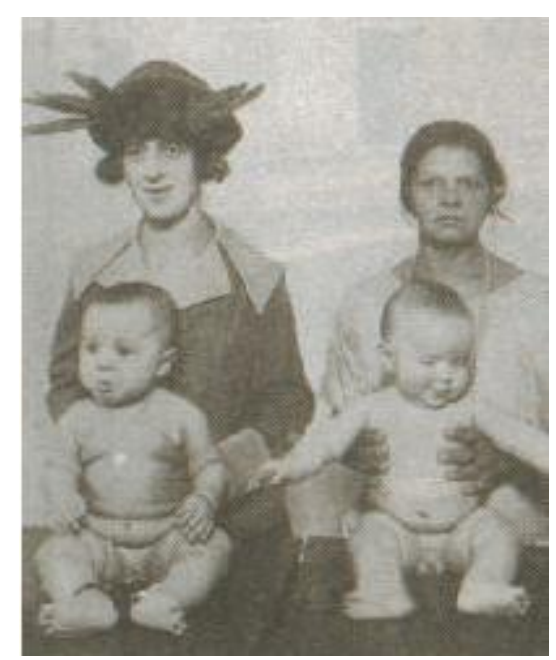

Figura 1: Ganhadores do Concurso de Robustez de 1928 (Fonte: Archivos de Protecção a I nfancia)

No ano de 1928, como se pode observar na Figura 1, os ganhadores do Concurso não fogem ao padrão estipulado. Os bebês brancos e gordos têm garantido o seu lugar de destaque como modelos do padrão de saúde e beleza hegemônico e valorizado pelos experts da saúde: os médicos.

Este modelo não foi propagado em vão: as teorias eugênicas em voga naquele momento exerciam grande influência nos discursos médicos. Como vimos anteriormente, os preceitos pautados em teorias científicas eram rapidamente assimilados pelas classes intelectuais e a eugenia não escapou desta fórmula.

A teoria, importada principalmente da Europa, encontrou eco no Brasil e teve como um de seus principais representantes Renato Kehl, médico, fundador da Sociedade Eugênica de São Paulo e ativista empenhado nas causas eugênicas e seus possíveis benefícios ao desenvolvimento e progresso do país. Destaque-se que em 1929 ocorreu o I Congresso Brasileiro de Eugenia e a criação do Boletim de Eugenia, idealizado pelo próprio Renato Kehl. Outra importante instituição de difusão dos ideais eugênicos no Brasil foi a Liga Brasileira de Higiene Mental, fundada em 1923 por Gustavo Riedel e composta por médicos de vários lugares do país. A Liga possuía um Boletim de grande circulação para o qual Moncorvo Filho escreveu alguns artigos. (SILVA JUNIOR; ANDRADE, 2007)

As preocupações eugênicas giravam em torno de questões como o aprimoramento racial sem perder de vista suas articulações e fundamentos que poderiam garantir a construção de uma nova identidade nacional, o que serviria como esteio para a consolidação de uma nova civilização, progresso e desenvolvimento social. (KOBAYASHI; FARIA; COSTA, 2009)

Nesse sentido, foram feitas várias campanhas tanto de esclarecimento da eugenia, como de persuasão a respeito de 
seus benefícios. Os argumentos vinham corroborar o anseio nacionalista de "ordem e progresso": uma nação só poderia progredir se tivesse um povo saudável e inteligente. Foram promovidos concursos eugênicos, sob a orientação do Serviço Sanitário do Estado de São Paulo, no qual foram premiadas crianças consideradas oficialmente eugenizadas. (CASTAÑEDA, 2003, p. 915)

Em síntese, a sintonia de Moncorvo Filho com o ideal eugênico também pode ser percebida por meio dos Concursos de Robustez realizados: mais do que uma simples estratégia de premiar crianças brancas e gordinhas, a atividade reproduzia em si todo um ideal intrínseco à ciência moderna e suas aspirações evolucionistas, não sendo raras as teses eugênicas que se apropriaram de referenciais como Galton, Malthus, Darwin e Mendel. Cada qual com suas particularidades e entendimentos epistemológicos, mas com um campo de interseção teórico capaz de instrumentalizar discursos e práticas voltados para um suposto melhoramento da espécie. Segundo Kobayashi, Faria e Costa (2009), não se pode falar em uma corrente eugênica única, tendo em vista as diversas variações deste movimento pelo mundo. No caso específico do Brasil, estes autores apontam que houve uma oscilação entre as diferentes doutrinas, com uma inclinação maior para os discursos preocupados com "a puericultura, a educação sexual e a orientação pré-natal" bem como para o estímulo ao "cruzamento entre os melhores" (p. 317).

\section{As Extensões do IPAI}

Uma das mais importantes extensões do IPAI foi o "Departamento da Creança no Brasil". Criado em março de 1919, teve como objetivo organizar informações a respeito da assistência à infância no país. Moncorvo Filho acreditava que um serviço como este proporcionaria elementos eficazes para ações futuras em benefício da infância. Deste modo, o Departamento atuou como uma agência de pesquisa e recolhimento de dados, cujas informações deveriam estar disponíveis aos interessados no tema da infância. Entretanto, o principal interesse de Moncorvo Filho era que, a partir do fornecimento de tais informações ao governo federal, esta agência pudesse se tornar o alicerce de um programa nacional de assistência infantil (WADSWORTH, 1999).

O Departamento foi mantido financeiramente com recursos próprios de Moncorvo Filho, que procurou, por vários meios, que o governo federal assumisse tal custeio. Entretanto, apenas em novembro de 1920 o Departamento foi reconhecido como de "Utilidade Pública Municipal" pelo decreto no 2.340, o que o credenciou a receber heranças e donativos. 
Este órgão funcionou até o ano de $1938 .^{5}$ Durante sua existência, além de reunir informações, promoveu a criação do Museu da Infância e a realização do I Congresso Brasileiro de Proteção à Infância.

A idéia da criação de um museu que relatasse, por meio de uma exposição, as condições de vida da criança e de sua mãe no caso do Brasil, com um recorte temporal que ia desde o descobrimento até aquela data - era originária de países europeus, resgatada por Moncorvo Filho com o mesmo objetivo, qual seja, exaltar o progresso da humanidade através da ciência. A comparação entre hábitos e instrumentos de épocas diferentes colocava em evidência o desenvolvimento das técnicas contemporâneas, em detrimento de práticas anteriores, consideradas rudimentares e primitivas.

Foram exibidos diagramas, quadros, fotografias, estatísticas, planos de instalação de creches, hospitais infantis, maternidades, asilos, ente outros documentos. A organização do Museu implicava numa classificação em 12 seções com os seguintes temas: Histórico, Legislação, registro e demografia; Puericultura; Hygiene Infantil; Hygiene Escolar; Analfabetismo; Infância Moralmente abandonada; Antropologia e Etnologia; Brinquedos e desportos; Filantropia à infância no Brasil; Comércio para a infância; Pinacoteca; Imprensa.

Não podemos perder de vista que, naquela época, a idéia de Museu estava associada apenas ao recolhimento e à guarda de documentos e objetos de uma história que se acreditava pronta ou acabada. Portanto, a ciência marcada pelo discurso de neutralidade garantiria a versão oficial e absoluta dos fatos. Era o que bastava. Não estava em questão que a própria seleção dos documentos e objetos a serem arquivados ou mostrados implicava em uma dada reconstrução da história. Desta forma, acreditava-se ser possível reconstruir a verdadeira história porque não existiria a possibilidade de outras interpretações.

Exaltava-se o uso da ciência como um dever patriótico para, através de seus recursos, alavancar o progresso do país. Além disso, as exposições deste tipo cumpriam a função de reafirmar idéias e valores hegemônicos, como se apresentassem a interpretação mais correta das realidades sociais e políticas. No caso do Museu da Infância:

Ele apresentou uma construção elitista a respeito do que deveria ser a nação, a infância e a assistência, procurando legitimar os programas de modernização propugnados pelas classes altas. (WADSWORTH, 1999, p. 8)

A inauguração do Museu aconteceu em 12 de outubro de 1922. Em somente três meses, já havia recebido 78.403 visitantes e até o ano de 1929 somavam-se 320 mil visitantes. 


\section{O I Congresso de Proteção à I nfância}

A primeira edição do Congresso de Proteção à Infância ocorreu no ano de 1922, organizado por Moncorvo Filho com o apoio do governo federal como parte das comemorações do Centenário da Independência.

O Congresso foi uma conquista do ponto de vista daqueles que faziam parte do movimento de proteção e assistência à infância. Tinha como principal objetivo reunir elementos de ação e produção de conhecimento em torno da infância brasileira que, de acordo com Moncorvo, eram muito dispersos. (SARTOR, 2000). O evento reuniu mais de 2600 participantes, "constituindo-se assim o mais concorrido no gênero que tem sido levado a effeito em todo mundo" (MONCORVO FILHO, 1929, p. 17). Entre estes participantes importa observar que se encontravam médicos, juristas, sociólogos, representantes de associações trabalhistas, de instituições educacionais, religiosas e filantrópicas, representantes das polícias estaduais, além de deputados. Destacamos ainda que, do número total de congressistas que apresentaram comunicações, apenas doze eram mulheres.

Desta forma, as mais de 250 memórias apresentadas no I Congresso mostravam conteúdos heterogêneos, vista a diversidade dos temas abordados a respeito da infância. As comunicações evidenciavam uma preocupação com as crianças pobres enquanto possível suposta força de trabalho, representando o futuro da nação. Tal idéia é bem representada pelo discurso de abertura do Congresso, proferido por Alfredo Ferreira de Magalhães, médico do estado da Bahia, em nome dos delegados oficiais dos estados do Brasil:

Precisamos ser coherentes e previdentes; o aproveitamento e avigoramento da creança representam a economia, o accréscimo das forças vivas da nacionalidade. Do que valem sacrifícios para trazer ao Brasil immigrantes quando deixamos emigrarem para a eternidade as creancinhas por falta de cuidados? O problema da creação dos meninos deixou de ser uma questão de ordem puramente familiar para abranger múltiplos interesses de ordem social. Uma creança que se perde, materil ou moralmente, não significa sómente uma saudade para a família, uma vergonha para os paes, é mais do que isto, uma força que se perde para a sociedade. Assim é em todos os períodos da infância; governantes e governados, em cada coletividade, precisam ter bem presentes estas verdades. O problema da creança é o máximo do problema social (...). É a própria sociedade que defendemos contra agressões, das quais, para ela mesma, o abandono das creanças constitui uma ameaça ou presságio. (apud SARTOR, 2000, p. 152) 
O entusiasmo dos participantes do I Congresso revela o destaque que o tema da infância passa a ter nas discussões políticas e intelectuais. Isto porque a instabilidade política e social da República Velha era uma forte ameaça às classes médias e altas que viam na propagação de um padrão de moralidade, saúde e bem-estar para as classes pobres um antídoto para o que se chamava na época de 'doença social'. Assim, a apropriação da infância como alvo de discussão, que deve ser assistido e protegido enquanto futuro da nação, evidencia a tentativa de um roteiro de construção de um país que não se baseia em políticas voltadas para a base dos problemas sociais como os salários baixos, pouco ou nenhum acesso à terra, mecanismos opressivos de controle social, saúde precária, falta de moradia e educação, mas na legitimação da entrada do especialista no núcleo familiar, ditando normas e modelos a serem seguidos, docilizando as classes ditas perigosas, com o objetivo final de preservar a ordem social, protegendo o futuro de seus próprios filhos.

As conclusões e recomendações do I Congresso revelam uma forte tendência para a centralização e o controle governamental da assistência infantil pública e privada. Sugeriu-se a regulamentação dos institutos de assistência à infância, a abolição das Rodas dos Expostos e a supervisão constante do poder público em relação a todos os aspectos referentes à assistência à infância. Além disso, o Congresso propugnou a criação de leis que reconhecessem os direitos das crianças à vida e à saúde, alertando para a necessidade da notificação obrigatória do nascimento e da instituição de atestados médicos que comprovassem a aptidão dos nubentes para 0 casamento, com o objetivo e evitar o nascimento de degenerados. Destacam-se ainda, as preocupações com a inexistência de leis que protegessem a mulher nas indústrias, sobretudo no período de gravidez, assim como o trabalho das crianças, o controle e prevenção de epidemias e a organização de estatísticas com o apoio da medicina, de modo a combater os problemas e reproduzir um número maior de trabalhadores sadios. De acordo com Wadsworth (1999), "Algumas das recomendações do congresso acabaram sendo incorporadas no Código de Menores de 1927." (p. 7)

\section{Considerações Finais}

A relevância dos trabalhos desenvolvidos por Carlos Arthur Moncorvo Filho, a respeito e em prol da infância e da maternidade, é inconteste na história recente do Brasil. Homem afinado com seu tempo, foi um importante representante da emergente classe de especialistas do inicio do século $X X$, patriota que via a ciência como instrumento na construção de uma nova nação. É reconhecido não só pela difusão do discurso de proteção à infância naquele período no Brasil mas também pela criação do IPAI, instituição que ganhou filiais em vários estados brasileiros. 
Retomar algumas histórias do IPAI significa dar visibilidade aos processos históricos que propiciaram a legitimação de discursos especialistas sobre a infância, a emergência do discurso científico como lugar de poder e as relações que o engendraram como tal.

Além disso, importa correlacionar o lugar de poder atribuído a estes discursos, produtores de um saber que pode normatizar, excluir, aprisionar, libertar, determinar valores e verdades. Compreender tais questões, a partir de reflexões sobre sua gênese, ajuda-nos a pensar/intervir nesta problemática conforme ela se configura hoje.

Afinal, os saberes "psi" têm ocupado lugar de destaque nos debates atuais sobre os modelos de ser e estar no mundo, tem sido chamados a ocupar espaços na escola, no poder judiciário, no hospital, na mídia etc. Precisamos questionar o modo como nós, enquanto especialistas, ocupamos ou não estes espaços. Estamos reproduzindo as práticas do início do século com novas roupagens? Estamos conseguindo criar novos rumos para nossas produções?

Só é possível responder a estas perguntas se criamos uma possibilidade de olhar para a história de modo a problematizar os cenários onde emergiram os saberes e fazeres que nos legitimam nos dias atuais. Isto não quer dizer prender-se ao passado, mas criar condições de, tomando a história como ferramenta, desnaturalizarmos nosso presente. Colocarmo-nos diante de uma análise em que nos despimos da carapaça despótica do especialista neutro e produtor de uma verdade pura.

A história do IPAI nos possibilita questionar o que nós, especialistas do início do século XXI, temos produzido em nome da ciência, entre discursos e práticas, a respeito das famílias e das infâncias.

\section{Referências Bibliográficas}

ARCHIVOS DE PROTECÇÃO A INFANCIA. Rio de Janeiro, v. 1, n. 1, novembro 1902.

ARCHIVOS DE PROTECÇÃO A INFANCIA. Rio de Janeiro, v. 5, n. 8, 1907.

CAPONI, S. Da Compaixão à Solidariedade: Uma Genealogia da Assistência Médica. Rio de Janeiro: Fiocruz, 2000.

CASTAÑEDA, L. A. Eugenia e casamento. História, Ciências, Saúde - Manguinhos, v. 10, n. 3, p. 901-930, Dez-2003.

COSTA, J. F. Ordem Médica e Norma Familiar. Rio de Janeiro: Graal, 1999.

DONZELOT, J. A Polícia das Famílias. Rio de Janeiro: Graal, 1986.

FREITAS, M. C. Para uma sociologia histórica da infância no Brasil. In: FREITAS, M. C. (Org.). História Social da I nfância no Brasil. São Paulo: Cortez, 1997.

JOSEPHSON, S. C. A Morte das Ruas: Estudo das Relações Entre Público e Privado nos Condomínios Exclusivos. 1994. $222 \mathrm{f}$. 
Dissertação (Mestrado em Psicologia) - Instituto de Psicologia, Universidade do Estado do Rio de Janeiro.

KOBAYASHI, E.; FARIA, L.; COSTA, M. C. Eugenia e Fundação Rockefeller no Brasil: a saúde como proposta de regeneração nacional. Sociologias, Porto Alegre, Ano 11, n. 22, p. 314-351, Dez. 2009.

LOBO, L. F. Os Infames da História: A Instituição das Deficiências no Brasil. 1995. Tese de Doutorado. Pontifícia Universidade Católica do Rio de Janeiro. Rio de Janeiro-RJ .

MANASĖRA, A. R.; SILVA, L. C. A Influência das Idéias Higienistas no Desenvolvimento da Psicologia no Brasil. Psicologia em Estudo, Maringá, v. 5, n. 1, p. 115-137, abr. 2000.

MATOS, M. I. S. Em nome do engrandecimento da nação: Representações de Gênero no discurso médico - São Paulo 1890$1930 . \quad$ Disponível em: <http://dhi.uem.br/publicacoesdhi/dialogos/volume01/vol04_atg2.ht m_edn1>. Acesso em: 13 nov. 2002.

MŌNCORVO FILHO, C. A. Amparemos à Infância! Rio de Janeiro, Typ. Villas Boas e C., 1915.

MONCORVO FILHO, C. A. A Assistência Publica e a Assistência Privada (Relações e Regulamentos) Rio de Janeiro: Departamento da Creança no Brasil, 1922.

MONCORVO FILHO, C. A. Histórico da Protecção à Creança no Brasil - 1500-1922. Rio de Janeiro: Departamento da Creança no Brasil, 1926.

MONCORVO FILHO, C. A. Alocução por ocasiãao da inauguração do edifício do Instituto de Proteção a Infância do Rio de Janeiro, em 14 de julho de 1929. Rio de Janeiro: Departamento da Creança no Brasil, 1929.

OLIVEIRA, L. A. Infância Pobre no Brasil: A Importância dos Discursos Psychologicos nas Instituições para Menores. In: J ACÓ-VILELA, A. M.; JABUR, F.; RODRIGUES, H. B. C. (Orgs.). Clio-Psiché: Histórias da Psicologia no Brasil. Rio de Janeiro: UERJ, NAPE, 1999, p. 115-124. RAGO, M. Do Cabaré ao Lar. A Utopia da Cidade Disciplinar. Rio de Janeiro: Paz e Terra, 1985.

REIS, J. R. F.: 'De pequenino é que se torce o pepino': a infância nos programas eugênicos da Liga Brasileira de Higiene Mental'. História, Ciências, Saúde - Manguinhos, Rio de Janeiro, v. 7, n. 1, p. 135157, mar.-jun. 2000.

RIZZINI, I. O Século Perdido: Raízes das Políticas Públicas para Infância no Brasil. Rio de Janeiro: Universitária Santa Úrsula, 1997

SARTOR, C. S. D. Proteção e Assistencia à Infância: considerações sobre o $1^{\circ}$ Congresso Brasileiro de Proteção a Infancia, rio de Janeiro, 1922. In: RIZZINI, I. (Org.). Crianças Desvalidas, indígenas e Negras no Brasil - Cenas da Colônia, do Império e da República. Rio de Janeiro: Universitária Santa Úrsula, 2000. 
SILVA JUNIOR, N. G. S.; ANDRADE, A. N. "É melhor pra você!": normatização social da infância e da família no Brasil. Revista do Departamento de Psicologia da UFF, Niterói, v. 19, n. 2, p. 423-438, Dez. 2007.

SOUZA, V. S.; SANTOS, R. V.; COELHO, M. C. S.; HANNESCH, O.; RODRIGUES-CARVALHO, C. Arquivo de Antropologia Física do Museu Nacional: fontes para a história da eugenia no Brasil. História, Ciências, Saúde - Manguinhos, v. 16, n. 3, p. 763-777, set 2009. WADSWORTH, J. E. Moncorvo Filho e o problema da infância: modelos institucionais e ideológicos da assistência à infância no Brasil. Revista Brasileira de História, São Paulo, v. 19, n. 37, p. 103-124, set. 1999.

\section{Endereço para correspondência}

Nelson Gomes de Sant'Ana e Silva Junior

Universidade Federal da Paraíba, UFPB, Praça João Pessoa, s/ noㅡ, Faculdade de Direito, Centro, CEP 58013-140, João Pessoa-PB, Brasil

Endereço eletrônico: nelsonjunior77@terra.com.br

Renata Monteiro Garcia

Universidade Federal da Bahia Rua 24 de Outubro, 184, Caixa Postal 304, Centro, CEP 47805-060, Barreiras-BA, Brasil

Endereço eletrônico: renatamonteirogarcia@terra.com.br

Recebido em: 24/03/2010

Aceito para publicação em: 10/05/2010

Acompanhamento do processo editorial: Ana Maria Jacó Vilela

\footnotetext{
Notas

* Psicólogo, Mestre em Psicologia.

**Psicóloga, Mestre em Psicologia Social.

${ }^{1}$ De acordo com Sartor (2001) estavam presentes 659 pessoas, entre elas: Arthur Azevedo, Alcindo Guanabara, Carlos Chagas, Coelho Netto, Evaristo de Moraes, Hermes da Fonseca, Joaquim Nabuco, José do Patrocínio, Lauro Müller, Lopes Trovão, Nilo Peçanha, Olavo Bilac e Quintino Bocaiuva.

${ }^{2}$ Segundo Moncorvo Filho foi a primeira instituição no mundo em matéria de assistência nestes moldes : “( ...) a brilhante creação do Dr. Gibert, do Harve, do Dispensario para doenças de creanças - a primeira instituição no mundo, então, fundada, constituindo, no genero, em materia de assistencia verdadeira novidade(...)" (1929, p. 9)

${ }^{3} \mathrm{Em} 5$ de novembro de 1924, o presidente Arthur da Silva Bernardes institucionalizou o dia 12 de outubro como o Dia Nacional das Crianças.

${ }^{4}$ Algumas vezes o Concurso foi realizado duas vezes no mesmo ano: no Dia das Crianças e no dia de Reis.

${ }^{5} \mathrm{Em}$ 1940, o governo federal criou o Departamento Nacional da Criança, no âmbito do Ministério da Educação e Saúde Pública, fornecendo os mesmos serviços que o Departamento criado por Moncorvo já prestava. Foi neste Departamento que Helena Antipoff atuou entre os anos de 1944 a 1949, participando da implementação do mesmo.
} 